Article

\title{
Formulation of the Effect of Different Alloying Elements on the Tensile Strength of the in situ Al-Mge Si Composites
}

\section{Halil Ibrahim Kurt* and Murat Oduncuoglu}

Technical Sciences, University of Gaziantep, 27310 Gaziantep, Turkey;

E-Mail: oduncuoglu@gmail.com

* Author to whom correspondence should be addressed; E-Mail: hiakurt@gmail.com; Tel.: +90-342-317-1700; Fax: +90-342-360-1170.

Academic Editor: Hugo F. Lopez

Received: 25 December 2014 / Accepted: 5 March 2015 / Published: 11 March 2015

\begin{abstract}
In this paper, the effect of different alloying elements on the ultimate tensile strength of $\mathrm{Al}-\mathrm{Mg}_{2} \mathrm{Si}$ composites is theoretically studied. The feed forward back propagation neural network with sigmoid function is used. The extensive experimental results taken from literature are modeled and mathematical formula is presented in explicit form. In addition, it is observed that magnesium and copper have a stronger effect on the ultimate tensile strength of $\mathrm{Al}-\mathrm{Mg}_{2} \mathrm{Si}$ composites comparison to other alloying elements. The proposed model shows good agreement with test results and can be used to find the ultimate tensile strength of $\mathrm{Al}-\mathrm{Mg}_{2} \mathrm{Si}$ composites.
\end{abstract}

Keywords: $\mathrm{Al}-\mathrm{Mg}_{2} \mathrm{Si}$; composites; metal matrix composites; modeling

\section{Introduction}

In the production of composite materials, aluminum ( $\mathrm{Al}$ ), magnesium $(\mathrm{Mg})$, titanium $(\mathrm{Ti})$ and nickel (Ni) alloys are commonly used as metal matrix. Among the materials, Al and its alloys are the most commonly used matrix material in the production of metal matrix composites (MMCs). The composites are manufactured with the diffusion bonding, power metallurgy and casting (also known as liquid metal infiltration) processes [1]. MMCs are widely used in various industries, especially in the automotive, energy and aerospace applications, as they have excellent mechanical properties. The need to reduce emissions while enhancing performance has driven manufacturers to use more $\mathrm{Al}$ in industry. 
This effort has been accompanied by the development of new Al alloys specifically tailored for these applications.

Al matrix composites (AMCs) reinforced by ceramic particles are prepared by in situ and ex situ methods. In the former method, the reinforce phase is synthesized internally in the matrix during the composite fabrication. In the latter method, the reinforce phase is synthesized externally and then added into the matrix during composite fabrication. The composites fabricated by these methods have important advantages such as good corrosion, high wear resistance, low cost, greater strength, compared to unreinforced materials [2,3]. Composites the produced by in situ technique exhibit the better particle wetting, even distribution of the reinforcing phase and thermodynamically stable system $[4,5]$.

$\mathrm{Al}-\mathrm{Mg}_{2} \mathrm{Si}$ composites constitute a new category of superlight materials attracting significant interest for potential applications. The $\mathrm{Mg}_{2} \mathrm{Si}$ intermetallic compound exhibits high melting point, low density, high hardness, low thermal expansion coefficient and reasonably high elastic modulus. The presence of $\mathrm{Mg}$ and silicon ( $\mathrm{Si}$ ) particles in the composite matrix with different alloying elements is considered to obtain the appropriate strength values and mechanical properties [6-8]. Additionally, the mechanical behaviors of the composites reinforced with particles were found to be a function of the matrix structure, addition alloying element, the volume fraction, particle size and shape of reinforcement [9].

The use of numerical modeling technique represents a new methodology in many different applications including materials science. One of the most used models is the artificial neural network (ANN), a form of artificial intelligence that has the ability to auto-analyze the relationship between multi-variable inputs without any hypothesis [10]. In many studies, the researchers reported that the ANN can be used as an efficient tool in predicting the properties of composite under given conditions and prescribed materials and the comparison of the designed $\mathrm{NN}$ and experimental results shows good agreement [11-15]. Expensive and time consuming tests are required for the determination of tensile properties of Al-based composites containing different additive element. The type and percent weight of alloying elements in the composition affect the ultimate tensile strength of the composite materials. Therefore, it is very important to select and add an element in different composition to obtain the maximum strength. The aim of this detailed theoretical study is to investigate the effect of different alloying elements on the tensile properties of in situ $\mathrm{Al}-\mathrm{Mg}_{2} \mathrm{Si}$ composites.

\section{Experimental Section}

The high cost-time for production and test is one of the most important barriers in the production new types of materials and composites. ANNs can accommodate multiple input variables to predict multiple output variables and are able to learn key information patterns within a multi information domain.

ANN is a mathematical model that performs a computational simulation of the behavior of neurons as in human brain and in nervous system. ANNs are capable of learning patterns by training with a number of known patterns. The learning ability of NNs procures an advantage in solving complex problems that are too difficult to solve with the analytical or numerical methods [16]. NN consists of the three components, namely: an activation function, weights and bias. Each neuron receives inputs, attached with a weight $w_{i}$, which shows the connection strength for that input for each connection. 
Each input is multiplied by the corresponding weight of the neuron connection. Next, a bias $\left(b_{i}\right)$ value is added to the summation of inputs and corresponding weights $(u)$ according to following equation:

$$
u_{i}=\sum_{j=1}^{H} w_{i j} x_{j}+b_{i}
$$

The summation $u_{i}$ is converted as the output with an activation (transfer) function, $f\left(u_{i}\right)$ yielding a value called the unit's "activation", as following formula:

$$
O=f\left(u_{i}\right) O
$$

\section{Dataset and Processing}

As the preprocessing of the data for ANN training, testing and validation of the models, each input and output variables are scaled to the range of 0 to 1 by the following the formula:

$$
x_{N}=\frac{x-x_{\min }}{x_{\max }-x_{\min }}
$$

where $x_{N}$ is the normalized value of variable $\mathrm{x}, x_{\max }$ and $x_{\min }$ are the maximum and minimum values of the variables, respectively. Output values resulted from ANN also in the range $[0,1]$ and transformed to its equivalent values based on reverse method of normalization technique [3]. The unnormalized method is as:

$$
x=x_{N}\left(x_{\max }-x_{\min }\right)+x_{\min }
$$

The ANN is trained and implemented using fully developed feed forward back propagation with sigmoid function. Neural network toolbox in Matlab is used in training of the ANN. The back-propagation is an effective, supervised and the most popular learning method that consists of an input layer, one or more hidden layers and an output layer [17-19]. Sigmoid function is an activation function joins curvilinear, linear and constant behavior depending on the values of the input in ANN system [20,21]. In the ANN, mean square error (MSE) and mean absolute error (MAE) are used as error evaluation criteria in order to facilitate the comparisons between predicted values and desired values. MSE and MAE were calculated by the program.

\section{Results and Explicit Formulation of NN Model}

The aim of this study is nominal strength prediction of $\mathrm{Al}-\mathrm{Mg}_{2} \mathrm{Si}$ composite materials containing different alloying elements. Therefore, an extensive literature survey has been performed for available experimental results [22-31]. The experimental datasets are divided into three sets as training, validation and test dataset to avoid the over fitting problems. The datasets for training, validation and test are randomly selected from among experimental results where 40 sets are training set as shown in Table 1, 9 sets are validation and test sets as shown in Table 2. 
Table 1. Training input data (wt.\%).

\begin{tabular}{|c|c|c|c|c|c|c|c|c|c|c|c|c|}
\hline Data Number & Mg & $\mathbf{S i}$ & $\mathbf{C u}$ & Mn & $\mathrm{Cr}$ & $\mathbf{P}$ & $\mathbf{B e}$ & B & $\mathbf{L i}$ & $\mathbf{Y}$ & $\mathbf{N a}$ & Al \\
\hline 1 & 16.2 & 9.1 & 0.01 & 0.03 & 0.02 & - & - & - & - & - & - & Rem. \\
\hline 2 & 16.2 & 9.1 & 0.01 & 0.03 & 0.02 & 0.1 & - & - & - & - & - & Rem. \\
\hline 3 & 16.2 & 9.1 & 0.01 & 0.03 & 0.02 & 0.5 & - & - & - & - & - & Rem. \\
\hline 4 & 16.2 & 9.1 & 0.01 & 0.03 & 0.02 & 3 & - & - & - & - & - & Rem. \\
\hline 5 & 9.5 & 5.5 & 0.01 & 0.01 & 0.02 & - & 0.1 & - & - & - & - & Rem. \\
\hline 6 & 9.5 & 5.5 & 0.01 & 0.01 & 0.02 & - & 0.5 & - & - & - & - & Rem. \\
\hline 7 & 9.68 & 5.7 & 0.02 & 0.02 & 0.01 & - & - & - & - & - & - & Rem. \\
\hline 8 & 9.68 & 5.7 & 0.01 & 0.01 & 0.52 & - & - & - & - & - & - & Rem. \\
\hline 9 & 9.68 & 5.7 & 0.01 & 0.01 & 1.02 & - & - & - & - & - & - & Rem. \\
\hline 10 & 9.68 & 5.7 & 0.01 & 0.01 & 2.02 & - & - & - & - & - & - & Rem. \\
\hline 11 & 9.5 & 5.5 & 0.01 & 0.01 & 0.02 & - & - & 0.1 & - & - & - & Rem. \\
\hline 12 & 9.5 & 5.5 & 0.01 & 0.01 & 0.02 & - & - & 0.5 & - & - & - & Rem. \\
\hline 13 & 9.7 & 5.5 & 0.01 & 0.01 & 0.02 & - & - & - & - & - & - & Rem. \\
\hline 14 & 9.7 & 5.5 & 0.01 & 0.51 & 0.02 & - & - & - & - & - & - & Rem. \\
\hline 15 & 9.7 & 5.5 & 0.01 & 1.01 & 0.02 & - & - & - & - & - & - & Rem. \\
\hline 16 & 9.7 & 5.5 & 0.01 & 2.01 & 0.02 & - & - & - & - & - & - & Rem. \\
\hline 17 & 9.7 & 5.5 & 0.01 & 3.01 & 0.02 & - & - & - & - & - & - & Rem. \\
\hline 18 & 9.7 & 5.5 & 0.01 & 5.01 & 0.02 & - & - & - & - & - & - & Rem. \\
\hline 19 & 9.7 & 5.5 & 0.01 & 0.01 & 0.02 & - & - & - & - & - & - & Rem. \\
\hline 20 & 9.7 & 5.5 & 0.01 & 0.01 & 0.02 & - & - & - & - & - & - & Rem. \\
\hline 21 & 9.7 & 5.5 & 0.01 & 0.01 & 0.02 & - & - & - & - & - & - & Rem. \\
\hline 22 & 9.7 & 5.5 & 0.01 & 0.01 & 0.02 & - & - & - & 0 & - & - & Rem. \\
\hline 23 & 9.7 & 5.5 & 0.01 & 0.02 & 0.01 & - & - & - & 5.5 & - & - & Rem. \\
\hline 24 & 9.74 & 6 & 0.01 & 0.01 & 0.03 & - & - & - & 6.12 & - & - & Rem. \\
\hline 25 & 9.47 & 7 & 0.01 & 0.01 & 0.02 & - & - & - & 7.11 & - & - & Rem. \\
\hline 26 & 9.54 & 11 & 0.01 & 0.02 & 0.03 & - & - & - & 1.37 & - & - & Rem. \\
\hline 27 & 9.7 & 5.5 & 0.01 & 0.02 & 0.01 & - & - & - & - & - & - & Rem. \\
\hline 28 & 9.7 & 5.5 & 0.01 & 0.01 & 0.02 & - & - & - & - & 0.1 & - & Rem. \\
\hline 29 & 9.7 & 5.5 & 0.01 & 0.01 & 0.02 & - & - & - & - & 0.5 & - & Rem. \\
\hline 30 & 9.7 & 5.5 & 0.01 & 0.01 & 0.02 & - & - & - & - & 1 & - & Rem. \\
\hline 31 & 9.7 & 5.5 & 0.01 & 0.01 & 0.02 & - & - & - & - & - & - & Rem. \\
\hline 32 & 9.7 & 5.5 & 0.01 & 0.01 & 0.02 & - & - & - & - & - & 0.01 & Rem. \\
\hline 33 & 9.7 & 5.5 & 0.01 & 0.01 & 0.02 & - & - & - & - & - & 0.05 & Rem. \\
\hline 34 & 9.7 & 5.5 & 0.01 & 0.01 & 0.02 & - & - & - & - & - & 0.08 & Rem. \\
\hline 35 & 9.7 & 5.5 & 0.01 & 0.01 & 0.02 & - & - & - & - & - & 0.15 & Rem. \\
\hline 36 & 9.82 & 5.7 & 0.11 & 0.01 & 0.01 & - & - & - & - & - & - & Rem. \\
\hline 37 & 9.82 & 5.7 & 0.31 & 0.01 & 0.02 & - & - & - & - & - & - & Rem. \\
\hline 38 & 9.82 & 5.7 & 0.51 & 0.01 & 0.02 & - & - & - & - & - & - & Rem. \\
\hline 39 & 9.82 & 5.7 & 1.01 & 0.01 & 0.02 & - & - & - & - & - & - & Rem. \\
\hline 40 & 9.82 & 5.7 & 5.01 & 0.01 & 0.02 & - & - & - & - & - & - & Rem. \\
\hline
\end{tabular}

The input (independent) variables are $\mathrm{Al}, \mathrm{Mg}, \mathrm{Si}$, copper $(\mathrm{Cu})$, manganese $(\mathrm{Mn})$, chromium $(\mathrm{Cr})$, phosphorus (P), beryllium (Be), boron (B), lithium (Li), yttrium (Y) and sodium (Na) wt.\%. The output 
(dependent) variable is the ultimate tensile strength (UTS) in unit of MPa. Levenberg-Marquardt (Trainlm) algorithm with back propagation is used in the training of NN.

Table 2. Validation and test input data (wt.\%).

\begin{tabular}{|c|c|c|c|c|c|c|c|c|c|c|c|c|c|}
\hline Part & Data Number & Mg & $\mathbf{S i}$ & $\mathbf{C u}$ & Mn & $\mathrm{Cr}$ & $\mathbf{P}$ & $\mathrm{Be}$ & B & $\mathbf{L i}$ & $\mathbf{Y}$ & $\mathbf{N a}$ & Al \\
\hline \multirow{9}{*}{ Validation } & 1 & 16.2 & 9.1 & 0.01 & 0.03 & 0.02 & 1 & - & - & - & - & - & Rem. \\
\hline & 2 & 9.5 & 5.5 & 0.01 & 0.01 & 0.02 & - & - & - & - & - & - & Rem. \\
\hline & 3 & 9.68 & 5.7 & 0.01 & 0.01 & 5.02 & - & - & - & - & - & - & Rem. \\
\hline & 4 & 9.7 & 5.5 & 0.01 & 0.01 & 0.02 & - & - & - & - & - & - & Rem. \\
\hline & 5 & 9.7 & 5.5 & 0.01 & 0.01 & 0.02 & - & - & - & - & - & - & Rem. \\
\hline & 6 & 9.66 & 6.5 & 0.01 & 0.01 & 0.02 & - & - & - & 6.45 & - & - & Rem. \\
\hline & 7 & 9.52 & 13 & 0.02 & 0.02 & 0.03 & - & - & - & 12.7 & - & - & Rem. \\
\hline & 8 & 9.7 & 5.5 & 0.01 & 0.01 & 0.02 & - & - & - & - & 0.3 & - & Rem. \\
\hline & 9 & 9.7 & 5.5 & 0.01 & 0.01 & 0.02 & - & - & - & - & - & - & Rem. \\
\hline \multirow{9}{*}{ Test } & 1 & 16.2 & 9.1 & 0.01 & 0.03 & 0.02 & 0.1 & - & - & - & - & - & Rem. \\
\hline & 2 & 9.5 & 5.5 & 0.01 & 0.01 & 0.02 & - & 0.3 & - & - & - & - & Rem. \\
\hline & 3 & 9.68 & 5.7 & 0.01 & 0.01 & 3.02 & - & - & - & - & - & - & Rem. \\
\hline & 4 & 9.5 & 5.5 & 0.01 & 0.01 & 0.02 & - & - & - & - & - & - & Rem. \\
\hline & 5 & 9.5 & 5.5 & 0.01 & 0.01 & 0.02 & - & - & 0.3 & - & - & - & Rem. \\
\hline & 6 & 9.5 & 5.5 & 0.01 & 0.01 & 0.02 & - & - & 1 & - & - & - & Rem. \\
\hline & 7 & 9.62 & 7.5 & 0.01 & 0.01 & 0.02 & - & - & - & 7.65 & - & - & Rem. \\
\hline & 8 & 9.7 & 5.5 & 0.01 & 0.01 & 0.02 & - & - & - & - & - & 0.2 & Rem. \\
\hline & 9 & 9.82 & 5.7 & 3.01 & 0.01 & 0.02 & - & - & - & - & - & - & Rem. \\
\hline
\end{tabular}

The performance of an $\mathrm{NN}$ is affected by the network architecture, initial weight and learning rate. One of the most difficult tasks in NN works is the determination of the number of hidden layers and the number of neurons in per layer. There is no well-defined procedure to find the optimal settings of parameters and network architecture. The trial and error approach is used to determine the number of neurons in the hidden layer. Three different neuron numbers in one hidden layer $(12,13$ and 14) are used in this study. The training data set $(70 \%)$ is used to determine the weights and learning ability of the network. It is known that increasing the data used in training process of $\mathrm{NN}$ enhances the learning ability of NN. After the network is trained, the validation dataset is used to measure the performance and generalization ability of the network. The test dataset is used to verify the effectiveness of the network and to estimate the expected performance in the future. It is observed that the optimal NN architecture is found to be 12-12-1 NN architecture with logistic sigmoid transfer function.

The experimental results are compared with the predicted results for the performance of NN model. Figure 1 shows the correlation of NN and experimental results for training set.

In the all stages of NN work, the effects of the percent weight of alloying elements on the strength of $\mathrm{Al}-\mathrm{Mg}_{2} \mathrm{Si}$ composites are quantified. The prediction accuracy of $\mathrm{NN}$ for training set is quite satisfactory. Severe deviations between the experimental and theoretical results are observed in training of $\mathrm{NN}$. These can be attributed to the sizes, volume fraction and morphology of $\mathrm{Mg}_{2} \mathrm{Si}$ phase and other phases formed in the matrix and variation in experimental conditions. It is known that the 
various geometric shapes of $\mathrm{Mg}_{2} \mathrm{Si}$ crystals and the formation and morphology of intermetallic phases have an important effect on the strength of $\mathrm{Al}-\mathrm{Mg}_{2} \mathrm{Si}$ composites [32].



Figure 1. Correlation of NN and experimental results for training set.

The correlation of NN and experimental results for validation and test sets are shown in Figure 2a,b, respectively. After the network is trained, the validation data (Figure 2a) are used to check that the model behaves correctly when presented with previously unseen data. The validation (15\%) and test $(15 \%)$ data sets are randomly selected by program from among 58 experimental data. It is not interfered to the program in the selection stage of the data sets. It is clearly seen from Figure 2 that the experimental and predicted values developed from ANN for UTS are very close to each other and it can also be seen a few minor deviations. The predictability ratio of proposed NN increases from training to test set.

The statistical parameters of training, validation and test datasets of the $\mathrm{NN}$ model is given in Table 3. In the train set, the observed correlation coefficient $(\mathrm{R})$ is 0.899 , which means that the performance of trained network model is acceptable. The model is verified against the cases in the test dataset, which are independent of the cases in the train dataset. The predicted results are plotted versus the experimental results. As shown in Table 3, the correlation coefficients of validation and test sets are 0.932 and 0.951 , indicating that the network can predict the UTS of $\mathrm{Al}-\mathrm{Mg}_{2} \mathrm{Si}$ composite materials with high accuracy and reliability. It can be said that the using of all the alloying elements with the different weight ratio in the training stage of $\mathrm{NN}$ is contributed to the increasing of $\mathrm{R}$ values of the validation and test sets. 

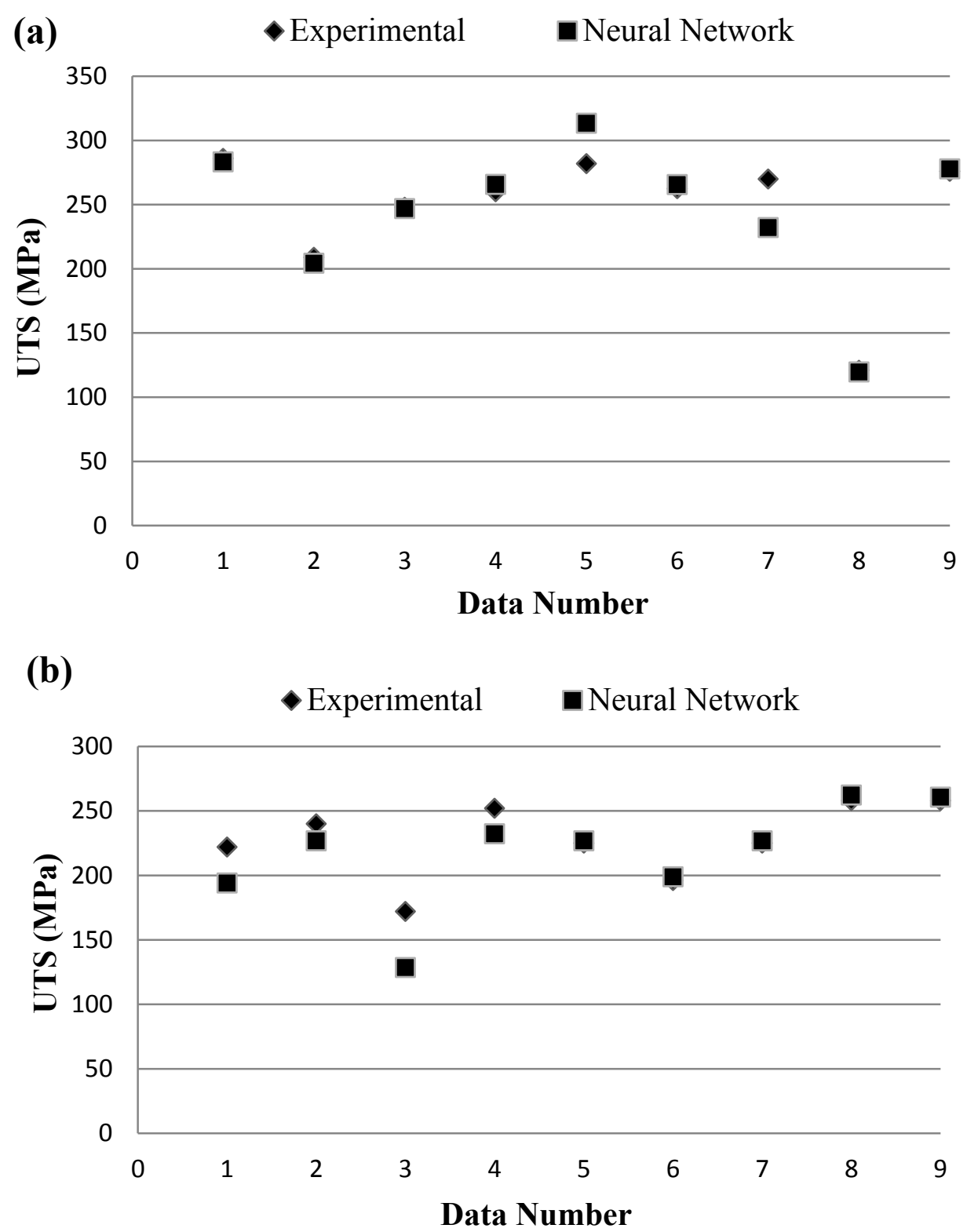

Figure 2. Correlation of neural network $(\mathrm{NN})$ and experimental results for (a) validation and (b) test sets.

Table 3. Statistical parameters of train, validation and test sets.

\begin{tabular}{cccc}
\hline Part & R & MSE & MAE \\
\hline Train set & 0.899 & 1.005 & 5.123 \\
Validation set & 0.932 & 0.706 & 5.765 \\
Test set & 0.951 & 0.537 & 4.385 \\
\hline
\end{tabular}

As mentioned before, the effects of the percent weight of alloying elements on the strength of $\mathrm{Al}-\mathrm{Mg}_{2} \mathrm{Si}$ are considered. The change in UTS values are probably due to the sizes, volume fraction and morphology of the phases and it needs extensive studies. Nevertheless, $\mathrm{R}$ values of training, validation and test sets indicate that the learning ability of $\mathrm{NN}$ is well enough and the proposed $\mathrm{NN}$ model has high accuracy. 
MSE and MAE are used to fix the performance of the proposed NN in prediction technique. MSE is $1.005 \%$ for training set, $0.706 \%$ for validation set and $0.537 \%$ for test set. If the MSE reaches zero, the performance of model is regarded as the excellent [13]. MAE is 5.123\% for training set, 5.765\% for validation set and $4.385 \%$ for test set. It is clear that the level of error decreases from training set to test set. These error criteria show that the main source of prediction error is the "noise" in the experimental data. These levels of error can be accepted and considered to be satisfactory. It can be said that the UTS of Al- $\mathrm{Mg}_{2} \mathrm{Si}$ composites can be predicted by ANN model with $95.1 \%$ accuracy and the presented $\mathrm{NN}$ model is in good agreement with the experimental data and all errors are within acceptable ranges. The sensitivity of input vectors on UTS of $\mathrm{Al}-\mathrm{Mg}_{2} \mathrm{Si}$ composites is given in Figure 3.



Figure 3. The sensitivity of input vectors.

The mechanical property of the in situ composites has a great relationship with the size and morphology of the $\mathrm{Mg}_{2} \mathrm{Si}$ phases [33]. It is seen that $\mathrm{Mg}$ has more impact on UTS of $\mathrm{Al}-\mathrm{Mg}_{2} \mathrm{Si}$ composites than the other alloying elements. Any change in $\mathrm{Mg}$ and $\mathrm{Cu}$ levels will have significant effect the UTS.

The main focus is to obtain the explicit formulation of UTS for Al- $\mathrm{Mg}_{2} \mathrm{Si}$ composites as a function of addition alloying elements. The proposed equation below is obtained using a developed macro in Matlab program. It should be noted that the proposed explicit formulation is valid for the ranges of training set.

$$
Y=227 \times\left(\frac{1}{1+e^{-w}}\right)+100
$$

where $Y$ is the ultimate tensile strength and $w$ is

$$
\begin{aligned}
& w=(-2.92) *\left(\frac{1}{1+e^{-u 1}}\right)+(0.19) *\left(\frac{1}{1+e^{-u 2}}\right)+(-2.66) *\left(\frac{1}{1+e^{-u 3}}\right)+(1.18) *\left(\frac{1}{1+e^{-u 4}}\right)+(0.66) *\left(\frac{1}{1+e^{-u 5}}\right)+ \\
& (-0.47) *\left(\frac{1}{1+e^{-u 6}}\right)+(1.30) *\left(\frac{1}{1+e^{-u 7}}\right)+(0.28) *\left(\frac{1}{1+e^{-u 8}}\right)+(2.29) *\left(\frac{1}{1+e^{-u 9}}\right)+(-4.70) *\left(\frac{1}{1+e^{-u 10}}\right)+(0.88) * \\
& \left(\frac{1}{1+e^{-u 11}}\right)+(-1.01) *\left(\frac{1}{1+e^{-u 12}}\right)+0.99
\end{aligned}
$$

where 


$$
\begin{aligned}
& u 1=(-0.81) * \mathrm{~K} 1+(1.70) * \mathrm{~K} 2+(1.24) * \mathrm{~K} 3+(-1.86) * \mathrm{~K} 4+(0.37) * \mathrm{~K} 5+(0.50) * \mathrm{~K} 6+(-0.21) * \mathrm{~K} 7+ \\
& (-0.92) * \mathrm{~K} 8+(-3.10) * \mathrm{~K} 9+(1.83) * \mathrm{~K} 10+(-0.85) * \mathrm{~K} 11+(0.20) * \mathrm{~K} 2+(0.47) \\
& u 2=(0.60) * \mathrm{~K} 1+(-1.29) * \mathrm{~K} 2+(-0.33) * \mathrm{~K} 3+(1.63) * \mathrm{~K} 4+(0.07) * \mathrm{~K} 5+(0.62) * \mathrm{~K} 6+(0.75) * \mathrm{~K} 7+(0.78) * \\
& \mathrm{~K} 8+(0.80) * \mathrm{~K} 9+(0.07) * \mathrm{~K} 10+(0.51) * \mathrm{~K} 11+(0.58) * \mathrm{~K} 2+(0.06) \\
& u 3=(0.19) * \mathrm{~K} 1+(-0.24) * \mathrm{~K} 2+(-2.11) * \mathrm{~K} 3+(-0.78) * \mathrm{~K} 4+(-0.09) * \mathrm{~K} 5+(-0.35) * \mathrm{~K} 6+(-0.66) * \mathrm{~K} 7+ \\
& (0.65) * \mathrm{~K} 8+(0.57) * \mathrm{~K} 9+(-0.08) * \mathrm{~K} 10+(0.88) * \mathrm{~K} 11+(0.58) * \mathrm{~K} 2+(-0.93) \\
& u 4=(0.57) * \mathrm{~K} 1+(-1.63) * \mathrm{~K} 2+(-0.88) * \mathrm{~K} 3+(1.56) * \mathrm{~K} 4+(0.31) * \mathrm{~K} 5+(0.02) * \mathrm{~K} 6+(0.43) * \mathrm{~K} 7+(0.75) * \\
& \mathrm{~K} 8+(1.57) * \mathrm{~K} 9+(-0.79) * \mathrm{~K} 10+(0.09) * \mathrm{~K} 11+(-1.16) * \mathrm{~K} 2+(0.51) \\
& u 5=(0.30) * \mathrm{~K} 1+(-1.08) * \mathrm{~K} 2+(-0.87) * \mathrm{~K} 3+(1.94) * \mathrm{~K} 4+(0.89) * \mathrm{~K} 5+(0.44) * \mathrm{~K} 6+(0.70) * \mathrm{~K} 7+(0.82) * \\
& \mathrm{~K} 8+(1.92) * \mathrm{~K} 9+(-0.03) * \mathrm{~K} 10+(0.73) * \mathrm{~K} 11+(0.89) * \mathrm{~K} 2+(0.43) \\
& u 6=(-0.10) * \mathrm{~K} 1+(0.47) * \mathrm{~K} 2+(0.24) * \mathrm{~K} 3+(-0.39) * \mathrm{~K} 4+(0.25) * \mathrm{~K} 5+(-0.06) * \mathrm{~K} 6+(0.09) * \mathrm{~K} 7+ \\
& (-0.51) * \mathrm{~K} 8+(0.22) * \mathrm{~K} 9+(0.11) * \mathrm{~K} 10+(0.04) * \mathrm{~K} 11+(0.12) * \mathrm{~K} 2+(0.36) \\
& u 7=(0.56) * \mathrm{~K} 1+(-0.33) * \mathrm{~K} 2+(-0.82) * \mathrm{~K} 3+(0.19) * \mathrm{~K} 4+(-0.69) * \mathrm{~K} 5+(0.07) * \mathrm{~K} 6+(0.65) * \mathrm{~K} 7+ \\
& (0.33) * \mathrm{~K} 8+(0.42) * \mathrm{~K} 9+(0.70) * \mathrm{~K} 10+(1.08) * \mathrm{~K} 11+(0.35) * \mathrm{~K} 2+(0.82) \\
& u 8=(0.49) * \mathrm{~K} 1+(-1.50) * \mathrm{~K} 2+(-0.70) * \mathrm{~K} 3+(0.90) * \mathrm{~K} 4+(0.57) * \mathrm{~K} 5+(0.17) * \mathrm{~K} 6+(0.20) * \mathrm{~K} 7+(0.13) * \\
& \mathrm{~K} 8+(0.91) * \mathrm{~K} 9+(0.03) * \mathrm{~K} 10+(0.69) * \mathrm{~K} 11+(0.82) * \mathrm{~K} 2+(0.53) \\
& u 9=(0.37) * \mathrm{~K} 1+(-0.79) * \mathrm{~K} 2+(-0.10) * \mathrm{~K} 3+(0.88) * \mathrm{~K} 4+(-0.08) * \mathrm{~K} 5+(0.03) * \mathrm{~K} 6+(0.42) * \mathrm{~K} 7+ \\
& (-0.06) * \mathrm{~K} 8+(-0.74) * \mathrm{~K} 9+(0.26) * \mathrm{~K} 10+(-0.65) * \mathrm{~K} 11+(-0.36) * \mathrm{~K} 2+(0.10) \\
& u 10=(1.21) * \mathrm{~K} 1+(1.26) * \mathrm{~K} 2+(-1.75) * \mathrm{~K} 3+(-1.79) * \mathrm{~K} 4+(-3.59) * \mathrm{~K} 5+(-1.40) * \mathrm{~K} 6+(-0.44) * \mathrm{~K} 7+ \\
& (-0.89) * \mathrm{~K} 8+(-0.68) * \mathrm{~K} 9+(0.22) * \mathrm{~K} 10+(-3.15) * \mathrm{~K} 11+(-2.48) * \mathrm{~K} 2+(-1.46) \\
& u 11=(0.23) * \mathrm{~K} 1+(-0.20) * \mathrm{~K} 2+(-0.47) * \mathrm{~K} 3+(0.18) * \mathrm{~K} 4+(-0.09) * \mathrm{~K} 5+(0.07) * \mathrm{~K} 6+(0.38) * \mathrm{~K} 7+ \\
& (-0.37) * \mathrm{~K} 8+(-0.68) * \mathrm{~K} 9+(0.70) * \mathrm{~K} 10+(-0.22) * \mathrm{~K} 11+(-0.07) * \mathrm{~K} 2+(0.22) \\
& u 12=(0.68) * \mathrm{~K} 1+(-0.33) * \mathrm{~K} 2+(-0.41) * \mathrm{~K} 3+(1.32) * \mathrm{~K} 4+(0.32) * \mathrm{~K} 5+(0.41) * \mathrm{~K} 6+(0.20) * \mathrm{~K} 7+ \\
& (0.74) * \mathrm{~K} 8+(0.49) * \mathrm{~K} 9+(-0.84) * \mathrm{~K} 10+(0.27) * \mathrm{~K} 11+(0.53) * \mathrm{~K} 2+(0.04)
\end{aligned}
$$

where $\mathrm{K} 1, \mathrm{~K} 2, \mathrm{~K} 3, \mathrm{~K} 4, \mathrm{~K} 5, \mathrm{~K} 56, \mathrm{~K} 7, \mathrm{~K} 8, \mathrm{~K} 9, \mathrm{~K} 10$, K11 and $\mathrm{K} 12$ are normalized input data of A1, Mg, $\mathrm{Si}, \mathrm{Fe}, \mathrm{Cu}, \mathrm{Mn}, \mathrm{Cr}, \mathrm{Ti}, \mathrm{Ni}, \mathrm{Zn}, \mathrm{P}, \mathrm{Zr}, \mathrm{Be}, \mathrm{B}, \mathrm{Li}, \mathrm{Y}$ and Na.

The training data set contains the weight percentage of all alloying elements and is used to determine the best set of neural network weights. Thus, the proposed equation can be used for determining the effects of all alloying elements on the strength of $\mathrm{Al}-\mathrm{Mg}_{2} \mathrm{Si}$ composites. It is observed that the strength of $\mathrm{Al}-9.5 \mathrm{Mg}-5.5 \mathrm{Si}-0.01 \mathrm{Cu}-0.01 \mathrm{Mn}-0.02 \mathrm{Cr}$ alloy used in test set with 3 wt.\% $\mathrm{Cu}$ increased from 252 to $317 \pm 12 \mathrm{MPa}$ using the derived formula. The multiple minor alloying elements $(0.02 \mathrm{P}+0.15 \mathrm{Be}+0.2 \mathrm{~B}+0.2 \mathrm{Y}+0.03 \mathrm{Na}$ wt.\% $)$ is theoretically added into 
Al-16.2Mg-9.1Si-0.01Cu-0.03Mn-0.02Cr alloy. The strength of the alloy is increased from 108 to $189 \pm 9 \mathrm{MPa}$. The main reason for this improvement can be attributed to the precipitation of more primary complex particles [34].

\section{Conclusions}

This work proposes an approach for ultimate tensile strength in prediction of $\mathrm{Al}-\mathrm{Mg}_{2} \mathrm{Si}$ composites containing different alloying elements. The back propagation NNs are used for the training process and the proposed NN model shows good agreement with experimental results. The results also demonstrate that all the data sets have quite high correlation and accuracy. Therefore, the mathematical function is derived in explicit form by using ANN. The outcomes of the study are very promising in general. The mean absolute error for predicted values does not exceed 5.8\%. The sensitivity analysis of the model demonstrated that the addition of $\mathrm{Mg}$ has greater effect than the other elements on the UTS of Al- $\mathrm{M}_{2} \mathrm{Si}$ composites. Hence it is concluded that considerable saving in terms of cost and time could be obtained by using the model and ANN is a successful analytical tool provided it is properly used.

\section{Author Contributions}

These authors contributed equally to this work. Kurt and Oduncuoglu analyzed and interpreted the data and prepared the manuscript. All authors discussed the conclusions and reviewed the manuscript.

\section{Conflicts of Interest}

The authors declare no conflict of interest.

\section{References}

1. Schwartz, M.M. Composite Materials: Processing, Fabrication, and Applications; Prentice Hall PTR: Upper Saddle River, NJ, USA, 1997.

2. Smith, W.F.; Hashemi, J. Foundations of Materials Science and Engineering; McGraw-Hill: New York, NY, USA, 2003.

3. Hassan, A.M.; Alrashdan, A.; Hayajneh, M.T.; Mayyas, A.T. Prediction of density, porosity and hardness in aluminum-copper-based composite materials using artificial neural network. J. Mater. Process. Technol. 2009, 209, 894-899.

4. Xu, C.L.; Wang, H.Y.; Yang, Y.F.; Jiang, Q.C. Effect of Al-P-Ti-TiC-Nd2O3 modifier on the microstructure and mechanical properties of hypereutectic Al-20 wt.\%Si alloy. Mater. Sci. Eng. A 2007, 452-453, 341-346.

5. Akrami, A.; Emamy, M.; Mousavian, H. The effect of bi addition on the microstructure and tensile properties of cast $\mathrm{Al}-15 \% \mathrm{Mg} 2 \mathrm{Si}$ composite über den einfluss der zumischung von bi auf die mikrostruktur und zugeigenschaften von gegossenen al-15\%mg2si verbunden. Materialwissenschaft und Werkstofftechnik 2013, 44, 431-435.

6. Jiang, Q.C.; Wang, H.Y.; Wang, Y.; Ma, B.X.; Wang, J.G. Modification of Mg2Si in Mg-Si alloys with yttrium. Mater. Sci. Eng. A 2005, 392, 130-135. 
7. Qin, Q.D.; Zhao, Y.G.; Liu, C.; Cong, P.J.; Zhou, W.; Liang, Y.H. Effect of holding temperature on semisolid microstructure of Mg2Si/Al composite. J. Alloys Compd. 2006, 416, 143-147.

8. Liao, L.-H.; Wang, H.-W.; Li, X.-F.; Ma, N.-H. Research on the dislocation damping of Mg2Si/Mg-9Al composite materials. Mater. Lett. 2007, 61, 2518-2522.

9. Shabani, M.O.; Mazahery, A. Prediction of wear properties in A356 matrix composite reinforced with $\mathrm{B}_{4} \mathrm{C}$ particulates. Synth. Metals 2011, 161, 1226-1231.

10. Yong, L.Z. Supervised classification of multispectral remote sensing image using BP neural network. J. Infrared Millim. Waves 1998, 2, 153-156.

11. Durmuş, H.K.; Özkaya, E.; Meriç, C. The use of neural networks for the prediction of wear loss and surface roughness of AA 6351 Aluminium alloy. Mater. Des. 2006, 27, 156-159.

12. Altinkok, N.; Koker, R. Modelling of the prediction of tensile and density properties in particle reinforced metal matrix composites by using neural networks. Mater. Des. 2006, 27, 625-631.

13. Sun, Y.; Zeng, W.D.; Zhang, X.M.; Zhao, Y.Q.; Ma, X.; Han, Y.F. Prediction of tensile property of hydrogenated Ti600 titanium alloy using artificial neural network. J. Mater. Eng. Perform. 2011, 20, 335-340.

14. Amirjan, M.; Khorsand, H.; Siadati, M.H.; Eslami Farsani, R. Artificial neural network prediction of $\mathrm{Cu}-\mathrm{Al}_{2} \mathrm{O}_{3}$ composite properties prepared by powder metallurgy method. J. Mater. Res. Technol. 2013, 2, 351-355.

15. Matlab, version 7.13; The MathWorks Inc.: Natick, MA, USA, 2011.

16. Rojas, R. Neural Networks: A Systematic Introduction; Springer: Berlin, Germany, 1996.

17. Hecht-Nielsen, R. Neurocomputing; Addison-Wesley Publishing Company: New York, NY, USA, 1990.

18. Rumelhart, D.E.; Hinton, G.E.; Williams, R.J. Learning internal representations by error propagation. Available online: http://psych.stanford.edu/ jlm/papers/PDP/Volume\%201/ Chap8_PDP86.pdf (accessed on 3 March 2015).

19. Cevik, A.; Kutuk, M.A.; Erklig, A.; Guzelbey, I.H. Neural network modeling of arc spot welding. J. Mater. Process. Technol. 2008, 202, 137-144.

20. Roiger, R.; Geatz, M. Data mining: A Tutorial-Based Primer; Addison Wesley: New York, NY, USA, 2003.

21. Larose, D.T. Neural networks. In Discovering Knowledge in Data; John Wiley \& Sons, Inc.: New York, NY, USA, 2005; pp. 128-146.

22. Yeganeh, S.E.V.; Razaghian, A.; Emamy, M. The influence of $\mathrm{Cu}-15 \mathrm{P}$ master alloy on the microstructure and tensile properties of $\mathrm{Al}-25 \mathrm{wt} \% \mathrm{Mg} 2 \mathrm{Si}$ composite before and after hot-extrusion. Mater. Sci. Eng. A 2013, 566, 1-7.

23. Azarbarmas, M.; Emamy, M.; Rassizadehghani, J.; Alipour, M.; karamouz, M. The influence of beryllium addition on the microstructure and mechanical properties of $\mathrm{Al}-15 \% \mathrm{Mg} 2 \mathrm{Si}$ in situ metal matrix composite. Mater. Sci. Eng. A 2011, 528, 8205-8211.

24. Ghorbani, M.R.; Emamy, M.; Nemati, N. Microstructural and mechanical characterization of Al-15\%Mg2Si composite containing chromium. Mater.Des. 2011, 32, 4262-4269.

25. Azarbarmas, M.; Emamy, M.; karamouz, M.; Alipour, M.; Rassizadehghani, J. The effects of boron additions on the microstructure, hardness and tensile properties of in situ $\mathrm{Al}-15 \% \mathrm{Mg} 2 \mathrm{Si}$ composite. Mater. Des. 2011, 32, 5049-5054. 
26. Ghorbani, M.R.; Emamy, M.; Khorshidi, R.; Rasizadehghani, J.; Emami, A.R. Effect of mn addition on the microstructure and tensile properties of $\mathrm{Al}-15 \% \mathrm{Mg} 2 \mathrm{Si}$ composite. Mater. Sci. Eng. A 2012, 550, 191-198.

27. Razaghian, A.; Bahrami, A.; Emamy, M. The influence of Li on the tensile properties of extruded in situ Al-15\%Mg2Si composite. Mater. Sci. Eng. A 2012, 532, 346-353.

28. Nasiri, N.; Emamy, M.; Malekan, A. Microstructural evolution and tensile properties of the in situ Al-15\%Mg2Si composite with extra Si contents. Mater. Des. 2012, 37, 215-222.

29. Emamy, M.; Jafari Nodooshan, H.R.; Malekan, A. The microstructure, hardness and tensile properties of $\mathrm{Al}-15 \% \mathrm{Mg} 2 \mathrm{Si}$ in situ composite with yttrium addition. Mater. Des. 2011, 32, 4559-4566.

30. Emamy, M.; Khorshidi, R.; Raouf, A.H. The influence of pure Na on the microstructure and tensile properties of Al-Mg2Si metal matrix composite. Mater. Sci. Eng. A 2011, 528, 4337-4342.

31. Emamy, M.; Nemati, N.; Heidarzadeh, A. The influence of cu rich intermetallic phases on the microstructure, hardness and tensile properties of Al-15\% Mg2Si composite. Mater. Sci. Eng. A 2010, 527, 2998-3004.

32. Li, C.; Wu, Y.Y.; Li, H.; Liu, X.F. Morphological evolution and growth mechanism of primary Mg2Si phase in Al-Mg2Si alloys. Acta Mater. 2011, 59, 1058-1067.

33. Zhang, J.; Wang, Y.-Q.; Yang, B.; Zhou, B.-L. Effects of Si content on the microstructure and tensile strength of an in situ A1/Mg2Si composite. J. Mater. Res. 1999, 14, 68-74.

34. Norman, A.F.; Hyde, K.; Costello, F.; Thompson, S.; Birley, S.; Prangnell, P.B. Examination of the effect of Sc on 2000 and 7000 series aluminium alloy castings: For improvements in fusion welding. Mater. Sci. Eng. A 2003, 354, 188-198.

(C) 2015 by the authors; licensee MDPI, Basel, Switzerland. This article is an open access article distributed under the terms and conditions of the Creative Commons Attribution license (http://creativecommons.org/licenses/by/4.0/). 